Article

\title{
A Systems Engineering Framework for Bioeconomic Transitions in a Sustainable Development Goal Context
}

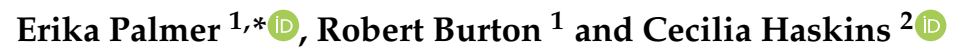 \\ 1 Ruralis-Institute for Rural and Regional Research, N-7049 Trondheim, Norway; rob.burton@ruralis.no \\ 2 Department of Mechanical and Industrial Engineering, Norwegian University of Science and Technology, \\ 7491 Trondheim, Norway; cecilia.haskins@ntnu.no \\ * Correspondence: erika.palmer@ruralis.no
}

Received: 3 July 2020; Accepted: 13 August 2020; Published: 17 August 2020

\begin{abstract}
To address sustainable development goals (SDGs), national and international strategies have been increasingly interested in the bioeconomy. SDGs have been criticized for lacking stakeholder perspectives and agency, and for requiring too little of business. There is also a lack of both systematic and systemic frameworks for the strategic planning of bioeconomy transitions. Using a systems engineering approach, we seek to address this with a process framework to bridge bioeconomy transitions by addressing SDGs. In this methodology paper, we develop a systems archetype mapping framework for sustainable bioeconomy transitions, called MPAST: Mapping Problem Archetypes to Solutions for Transitions. Using this framework with sector-specific stakeholder data facilitates the establishment of the start (problem state) and end (solution state) to understand and analyze sectorial transitions to the bioeconomy. We apply the MPAST framework to the case of a Norwegian agricultural bioeconomy transition, using data from a survey of the Norwegian agricultural sector on transitioning to a bioeconomy. The results of using this framework illustrate how visual mapping methods can be combined as a process, which we then discuss in the context of SDG implementation.
\end{abstract}

Keywords: systems engineering; bioeconomy; Sustainable Development Goals (SDGs)

\section{Introduction}

A central motivation for developing a bioeconomy is to foster "a continuing evolutionary process of transition from systems of mining non-renewable resources to farming renewable ones" [1] (p. 1)—an objective that ties the transition closely to the UN Sustainable Development Goals (SDGs) [2,3]. The SDGs are a network of interconnected goals used as a reference for the international community in working towards sustainable development [4-6]. Yet, an analysis of the SDGs has found them to be weak on agency, while requiring little from governments and nothing from business or consumers [7]. The SDGs focus on the state and impact, ignoring conflict and stakeholder knowledge of the issues $[8,9]$ and the pressures and drivers that counteract each other in competing impact categories in the same or different geographic contexts [7]. This is of particular importance in bioeconomic transitions, as agriculture has an important role in the bioeconomy and land use has a significant impact on the environment [10], with Norway as no exception [11]. In addition, the economic development of rural areas in a bioeconomy is unclear [12]. As the ambition of individual states varies, the focus on state implementation of policies for increasing SDG impact means that targets will not be realized or there must be new strategies for implementation. If bioeconomy transitions are to be used to reach SDGs, new methods are needed to incorporate stakeholder perspectives and understand counteracting drivers and pressures in the SDG network for successful policy implementation. In the bioeconomy, there is a 
specific concern that policy implementation will be outside cultural norms in farming communities [13] and will require collaborative action within these communities to be successful [14]. In addition, there is an established need to consider citizens and other stakeholders disrupted by bioeconomy transitions [15].

Within this context, the conceptualization of bioeconomy transitions together with meeting SDGs naturally lends itself towards to systems engineering because SDGs are easily framed in a systems theoretical context [16], and capacity building to meet SDGs has been argued to require systems thinking [17]. System archetypes [18,19] can be helpful to gain insight into patterns of behavior, especially in contexts of interconnected and competing goals [20]. In addition, SDGs intersect many societal domains, and a systems approach to investigating persistent social and environmental problems has been shown to help policymakers tackle the complexity associated with many intersected societal domains [21]. Concerning using systems archetypes as part of a methodological design, however, there needs to be a systematic method for mapping archetypes rather than an arbitrary assignment of a generic system structure to a specific situation [22]. This systematic mapping requires an identification of a problem archetype to a solution archetype (the start and end points in a transition) with an identified path between the problem and solution. For mapping bioeconomy transitions, this mapping needs to be nested in the SDG network in order to complement national and international strategies that seek to use the bioeconomy as a means of reaching SDGs, and which can be complementary to SDG mapping [23].

We use systems engineering as the approach for developing a framework for a systematic and systemic mapping of bioeconomic transitions in an SDG context because bioeconomic transitions are transitions within and between socio-technical systems [24], and systems engineering has the potential to significantly contribute to the evaluation of socio-technical systems [22]. Systems engineering is developing ways to evaluate systems in social domains [25], and this paper provides a new arena in which to apply systems engineering methods: the bioeconomy. In this paper, we develop a framework for applying a qualitative systems engineering method: visual systems mapping. Qualitative methods in systems engineering have been cited as being useful in the evaluation of socio-technical systems because of their high degree of "messy complexity", making quantitative methods much more difficult to apply [26]. Szajnfarber \& Gralla (2017) specifically mention the use of visual mapping techniques for systems engineers for process-orientated analysis (in this case, transition processes).

Figure 1 illustrates the connection between systems engineering, bioeconomy transitions and SDGs. Why are SDGs part of this process? The context of SDGs provides feedback for the success of bioeconomic transitions. Since the bioeconomy is being used as a means to meet SDGs, a bioeconomy transition should be planned and evaluated in an SDG context. The SDGs can then be used as performance indicators of the transition. This then leads to the question of: how do we plan and evaluate a bioeconomy transition in an SDG context? Using a systems engineering approach, this paper addresses this question by developing framework for applying visual systems mapping techniques. In doing so, we address the lack of social science inclusion in the study of bioeconomic transitions [9]. 


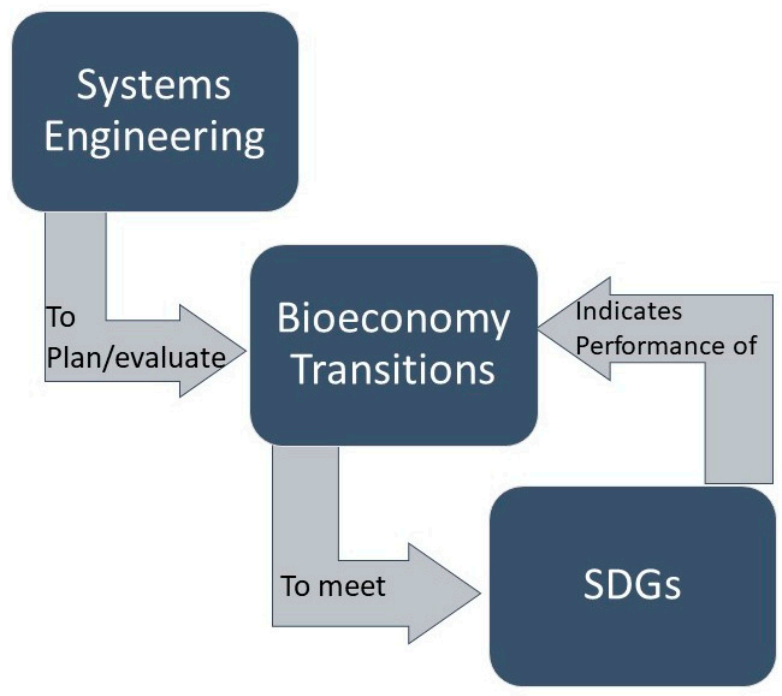

Figure 1. Relationship between Systems Engineering, Bioeconomic Transitions and Sustainable Development Goals (SDGs).

This is a methodological paper, where we use empirical data to develop the methodological framework. Although we are working within systems theory to develop this framework, we do aim for a theoretical contribution. The paper's aim is two-fold. First, it seeks to build upon previous archetype mapping methods in sustainability science to provide a system archetype process framework for use in bioeconomy transitions in an SDG context [18,19,27-29]. We do not provide a new framework for SDG modeling and scenarios (e.g., [30]), but rather build a process framework to bridge bioeconomy transitions while addressing SDGs. Second, this paper applies this framework on sustainable bioeconomy transitions in Norwegian agriculture. Given the brief background provided in this introduction, the next section outlines the process framework (called MPAST: Mapping Problem Archetypes to Solutions for Transitions) and the background on the framework application in the Norwegian bioeconomy transition. The following section provides the results of the mapping framework application, which is then discussed in the context of the SDGs. Lastly, this paper provides areas for future research and for framework development in a more general context.

\section{Systems Mapping for Bioeconomy Transitions}

Systems mapping for the purposes of this study is the qualitative modeling of a system that describes problematic and solution-orientated system conditions. We do not develop new system mapping techniques but instead develop a process framework for applying them in bioeconomic transitions. We do this because there are competing visions (solution states) of the bioeconomy, and different sectors in the bioeconomy will have different pathways for reaching solution states [31,32]. The application of system archetypes and mapping them in this context requires a more rigorous sector specific methodology than a simple selection of established system archetypes from those established by systems thinking practitioners (e.g., [19]), which is why we developed a process framework for applying them (within the agricultural sector). The background to the case application of this method is Norwegian bioeconomy transitions. To ground the reader in the description of the methodological design, we begin with a short background on the Norwegian bioeconomy.

\subsection{Bioeconomy Transitions in Norway}

One of the problems with transitioning to a bioeconomy is that while the development of a bioeconomy in Norway necessitates integrated development across sectors, multiple actors and institutions [33,34], industrial economies are siloed and sectorial. Each works on separate problems, has different stakeholders and is guided by independent governance/policy-regimes (i.e., 
different ministries). To achieve integration, Norway's National Bioeconomy Strategy prioritizes the development of cross-sectoral value chains in four areas, namely; cross-sectoral cooperation, markets for bio-based products, processing of biological products and sustainable extraction of bio-based products [35].

Within this framework, agriculture plays an economically limited, but politically important role and is a key sector in the bioeconomy. Since 1972, the maintenance of rural communities has been a key policy goal in Norway, with considerable amounts of public money flowing into decentralizing funds and initiatives [36]. Agricultural bioeconomy developments also feature in government policies to enhance food security and reduce climate emissions. Here, its main sectoral integrations are as consumers of bioeconomic solutions for feed production (high-protein biosynthesized animal feed from forestry to replace imported soy meal) and utilization of residual materials and waste (including biogas) [35]. Overall, Norway's vision of a bioeconomy transition is a fully integrated one and "encompasses all sectors and related services, which produce, process or use biological resources in whatever form" [37] (p. 15). In Norway, agriculture is a key part of this vision, as "it produces for a protected domestic market and is expected to achieve such policy goals as food security, food sovereignty, rural settlement and employment, and the maintenance of agricultural land and cultural landscapes" [32] (p. 11).

\subsection{MPAST: Mapping Problem Archetypes to Solutions for Transitions}

The systems mapping framework we developed for bioeconomy transitions is called MPAST: Mapping Problem Archetypes to Solutions for Transitions. Essentially, the MPAST framework identifies the start and finish lines for evaluating bioeconomy transitions by sector. MPAST is a "framework of frameworks", where it facilitates the systematic application and validation of established system archetypes to bioeconomy transitions. We do not develop established frameworks but put them together in a new way, and there are many different methods for analysis that can be built into each of the phases. There are three phases to this framework: Phase 1-start (problem state); Phase 2 -end (solution state); and Phase 3-pathway. There are start and end points for transitions (Phases 1 and 2): we transfer from one (problematic) system condition/state to a new (solution) system condition/state. In a systems approach, these start and end points can be conceptualized as problem archetypes and solution archetypes. Between the start and ends points and their mapped archetypes is the pathway from problem to solution (Phase 3)—see Figure 2 for an overview.

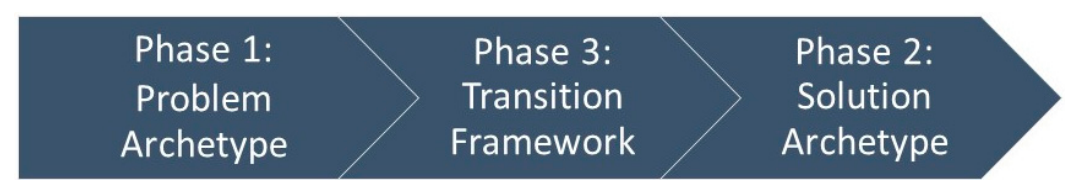

Figure 2. Mapping Problem Archetypes to Solutions for Transitions (MPAST) Process Framework. The phases are the methodological application sequence; the order in the figure is the transition process sequence.

\subsubsection{Problem Archetypes (MPAST)-Phase 1}

A system archetype is a generic qualitative description of a system structure that leads to problematic behavior or unintended consequences over time [18]. There are ten system archetypes that are generally acknowledged by systems thinking practitioners [19]. Although established as "archetypes" in academic literature, this does not have to be the only list that those using archetype mapping can look for to identify a system structure that describes a problematic system structure. Any system model that describes a problematic behavior can be applied in the MPAST framework. System archetypes in systems thinking are generic but not comprehensive for all problematic system behavior. Another example beyond the traditional system archetypes is the list of syndromes. Syndromes are a scaled-approach that identifies qualitative sub-models on an intermediate level that 
work towards global change [28,38]. As described in Section 2.1, the Norwegian bioeconomy and its competing stakeholder perspectives by sector lends itself well to the use of syndromes in the application of MPAST. The requirement of Phase 1 of MPAST application is that the problematic archetypes chosen to describe the initial system condition in a transition. In a participatory mapping session, this would require the stakeholders to acknowledge that the chosen problem archetype describes the system well. To validate the chosen problem archetype without stakeholders requires validation through consultation with subject matter experts (SMEs).

\subsubsection{Solutions (MPAST)-Phase 2}

The solution phase in MPAST may or may not depend on the set of problem archetypes chosen in Phase 1. If, for example, system archetypes outlined by Braun (2002) [19] are chosen to describe the problem, these archetypes also provide the solution archetype as well. However, when mapped onto the specific bioeconomy transition problem, the solution may have to be adapted. There are independent solution archetype sets that can be applied in Phase 2; for example, specifically for climate change, see Eisenack (2012) [39]. A helpful, extensive example of sustainable business model archetypes as solutions that can be applied to the bioeconomy is by Bocken et al. (2014) [27]. Validation of the solution archetype-i.e., knowing whether the solution of the bioeconomy end goal for a specific sector in a bioeconomy transition is a solution to the problem state (phase 1)-requires empirical evidence in scientific literature. For example, in the bioeconomy, creating value through waste with industrial symbiosis as a business model would be an empirically validated solution to a waste-based bioeconomy transition [40].

\subsubsection{Transitions (MPAST)-Phase 3}

For the bioeconomy, transitions require the society to change from one that mines non-renewable resources to a society that farms renewable resources [1]. A shift in system conditions has been cited as a requirement of bioeconomy transitions [32]. For transitions in MPAST, it is possible to use many pathway frameworks that work systematically towards a change in system states. The requirement of Phase 3 is that there is a systematic process for transitioning from Phase 1 to Phase 2. Methodological approaches to mapping transitions are found in fields such as strategic planning and systems engineering. For example, backcasting is a well-established strategic planning method often used in sustainability science [41]. Validation of Phase 3 depends on the transitioning framework chosen.

As we will explain in Section 3, we have chosen a framework for bioeconomy transitions from systems engineering-PADE. SPADE is an acronym, which stands for: Stakeholders, Problem Formulation, Analysis, Decision-Making and Evaluation [22]. SPADE is a non-sequential research process, each part can be taken individually or several simultaneously, and iteratively.

In the following section, we apply the MPAST framework to a sector-specific bioeconomy transition evaluation.

\section{Case Analysis: Application of the MPAST Framework}

For each of the phases in MPAST, we were informed by data from a survey given as part of a project that aimed to promote a smart transition to the bioeconomy [42]. The aim of the survey was to identify how different relevant sectors in the bioeconomy believe that the bioeconomy will look like in 2030, and what role they envisage playing in this economy. The survey was given to businesses and other stakeholders (e.g., R\&D, advisory services) in sectors that have a connection to the bioeconomy. This included sectors such as industry, education and research, but also primary industries such as agriculture, forestry and fisheries. In total, there were 1313 survey respondents. We have chosen agriculture for the sector-specific bioeconomy transition evaluation using the MPAST framework. Norwegian agriculture is an interesting case for examining bioeconomy transitions because Norway's approach to developing a bioeconomy is a particularly integrated one [37], and as mentioned 
in Section 2.1 is meant to serve multiple goals: "food security, food sovereignty, rural settlement and employment, and the maintenance of agricultural land and cultural landscapes" [32] (p. 11). The survey data and analysis can be accessed through the link provided in the reference list [42].

\subsection{Application: Problem Archetypes (MPAST)-Phase 1}

When we began this analysis, the intention was to use traditional system archetypes summarized by Braun (2002) [19] for application in Norwegian agriculture bioeconomy transitions. However, we felt that these were not specific enough to environmental challenges in Norwegian agriculture, and we found that using syndromes of global change $[28,38]$ was a better fit. Syndromes are sets of underlying actions that have consequences (symptoms). For example, the overexploitation of natural ecosystems is a syndrome that leads to a host of environmental problems that are symptoms (e.g., loss of biodiversity) of the underlying syndrome. In Phase 1, we identified each of the syndromes that were applicable to Norwegian agriculture bioeconomy transitions based on the survey data. Table 1 lists these syndromes and their meaning.

Table 1. Applied Syndrome in MPAST Phase 1 from Schellnhuber et al. (2002) [28].

\begin{tabular}{cc}
\hline Syndrome Name & Syndrome Meaning \\
\hline Sahel Syndrome & Overcultivation of marginal land \\
Overexploitation Syndrome & Overexploitation of natural ecosystems \\
Dust Bowl Syndrome & Non-sustainable agro-industrial use of soils and bodies of water \\
Aral Sea Syndrome & Environmental damage of natural landscapes as a result of large-scale projects \\
Green Revolution Syndrome & Environmental degradation through the introduction of inappropriate farming methods \\
\hline
\end{tabular}

The syndromes in Table 1 act as the initial starting point in bioeconomy transitions for Norwegian agriculture. These issues must be solved by the solution phase of MPAST.

\subsection{Application: Solutions (MPAST)-Phase 2}

In Phase 2 of MPAST, we map solution archetypes to the problem archetypes identified in Phase 1. Syndromes as problem archetypes do not have prescribed solution archetypes. Bocken et al. (2014) [27] provide sustainable business model archetypes that fit well in a Norwegian agricultural bioeconomy transition context. The reason for this is because the archetypes are specific to business models, and business stakeholders by sector was the focus of the survey used in this analysis. Two sustainable business archetypes address the syndromes listed in Table 1 (see Table 2).

Table 2. Mapping solution archetypes to problem archetypes for Norwegian agriculture bioeconomy transitions.

\begin{tabular}{cc}
\hline Problem Archetypes-Syndromes [28] & Solutions-Sustainable Business Archetypes [27] \\
\hline $\begin{array}{c}\text { Sahel Overexploitation Dust Bowl Aral Sea } \\
\text { Green Revolution }\end{array}$ & $\begin{array}{c}\text { Adopt a Stewardship Role } \\
\text { Repurpose for Society and the Environment }\end{array}$ \\
\hline
\end{tabular}

The sustainable business archetypes by Bocken et al. (2014) [27] give examples of how these solutions can be achieved. For example, in adopting a stewardship role, a business can create a business model that focuses on biodiversity protection. However, there is a pathway to reaching these end goals, and development of the specific business model is an iterative process, which we discuss in the next phase of MPAST.

\subsection{Application: Transitions (MPAST)-Phase 3}

As mentioned, we used the SPADE, which is "a streamlined methodology that is visually representative of the intrinsically iterative nature of systems engineering" [29] (p. i). We chose one solution in Table 2 to evaluate further based on the opinions of farmers towards bioeconomy goals in 
the survey: Adopt a Stewardship Role. We organized the results of the SPADE analysis for MPAST Phase 3 in Table 3.

Table 3. Overview of SPADE Analysis.

\begin{tabular}{ccccc}
\hline & & SPADE Analysis & & \\
\hline Stakeholders & Problem & Analysis & Decision/Tradeoffs & Evaluation \\
\hline Farmers Agri-Business & & & & \\
Local/Rural Communities & Energy Sources & Income and & Iterative evaluation of \\
Consumers Cooperative & Waste Soil & Resource & Financing & the S,P,A,D parts of \\
Agricultural Supplier & depletion Markets & Stewardship & Heritage/Cultural & SPADE framework \\
Academia/Research & & & Identity & \\
Politician Environment & & & & \\
\hline
\end{tabular}

When conceptualizing the role of the SPADE framework and how to use it, we need to clarify its role in MPAST. Table 4 shows this organization. Phases 1 and 2 set the goal posts of where a sector is and where it needs to go in terms of bioeconomy transitions for a specific identified problem archetype in one sector. For the SPADE analysis, the overexploitation syndrome with the "adopt a stewardship role" was the best fit from the survey results as a solution for agriculture. The Phase 3 analysis of MPAST organizes elements to begin transitioning from overexploitation to stewardship.

Table 4. Overview of the MPAST Application to Norwegian Agriculture Bioeconomy Transitions.

\begin{tabular}{cccc}
\hline MPAST & Phase 1: Problem Archetype & Phase 3: Transition to & Phase 2: Solution Archetype \\
\hline $\begin{array}{c}\text { Archetypes } \\
\text { Set/Framework }\end{array}$ & Syndromes & SPADE & $\begin{array}{c}\text { Sustainable Business } \\
\text { Model Archetypes }\end{array}$ \\
\hline Analysis & Overexploitation & $\begin{array}{c}\text { Resource Stewardship } \\
\text { Iterative Pathway }\end{array}$ & Adopt a Stewardship Role \\
\hline
\end{tabular}

Referring to Table 3, the stakeholders part of SPADE is necessary to make sure that the problem archetype (Phase 1) and solution archetype (Phase 2) includes all the relevant stakeholders. This may have already been systematically covered in Phase 1 and 2 depending on which archetypes were chosen, but Phase 3 ensures that they have been identified. The stakeholders listed in Table 3 were provided in the application of MPAST by the survey (in addition to the environment, which must be included as a stakeholder in sustainability analysis). The problem part of SPADE lists the problems (symptoms related to syndromes in this application) that were identified in Phase 1. The analysis part of SPADE lists the solution archetype identified in Phase 2. The decision/tradeoffs part of SPADE identifies structural issues (in this case identified by the stakeholders from the survey) that inhibit the transition from Phase 1 to Phase 2. The evaluation part of SPADE is an iterative evaluation of the stakeholders, problems, analysis and decisions/tradeoffs over time. This is a non-sequential transition analysis that can be updated as new data sources are used, new stakeholders are included and problem and solution states (Phases 1 and 2) shift. We used survey data to begin the process of analyzing a bioeconomy transition for Norwegian agriculture, but once started, this is an agile process, and no pathway analysis is set in stone. What we mean by this is that no analysis is final, and future work makes transition pathways clearer over time.

In the bioeconomy, we are transitioning from non-renewable to renewable resources. This can lead to the overexploitation of renewable resources [43], and a sustainable business model must exercise a stewardship role of the renewable resources. For this transition, it is critical to identify all relevant stakeholders to increase policy implementation success (in addition to reasons of social justice). In agriculture, the problems in the transition are (among others) energy sources, waste, soil depletion and markets. To begin a transition to resource stewardship, decisions/tradeoffs must be made. Agricultural stakeholders in the survey had many concerns related to income and financing 
and cultural heritage in bioeconomy transitions, which were identified as structural issues that inhibit the transition in the SPADE analysis.

In a more concrete example, "laboratory meat," despite its controversial status, offers a strong illustrates how bioeconomic development (protein synthesis) could both improve food security and address climate change as new industrial and scientific applications create entirely new platforms of industrial production, eradicating the need for existing farming systems in particular product sectors [44]. However, the energy consumption of the necessary bioreactors may be considerable, necessitating a move to renewable energy sources if sustainability is to be assured [45]. We can identify in this example competing SDG pressures (which we discuss in the next section), where a bioeconomy transition is a solution (farming renewable energy sources). The new market for laboratory meat and the energy sources are both identified problems in the SPADE analysis. The sustainable business model needs a resource stewardship role, which needs to be iteratively designed in consultation with stakeholders. Designing the transition with stakeholders must address the structural issues identified in decisions/tradeoffs: income/financing and cultural heritage/identity. For laboratory meat, this means the design must address the questions of: how new markets are going to affect farmer income; how they are going to finance transitioning to new markets; how will farming as part of cultural heritage and farmers' cultural identity affect or be affected by this transition; and how will renewable energy resources be sustainably harvested?

MPAST does not answer these questions, but it does identify, organize and gives power to stakeholder voices in setting the goal posts of bioeconomy transitions and in the iterative process of designing the pathway between the goal posts. In the next section, we discuss this in the context of SDGs.

\section{Discussion: MPAST and SDGs}

Using a systems engineering approach, the methodological framework developed in this paper seeks to build upon previous archetype mapping methods in sustainability science for use in in bioeconomy transitions. In addition, MPAST seeks to strengthen the use of qualitative methods in systems engineering for the evaluation of socio-technical systems [26]. The MPAST framework provides a process for applying visual systems mapping to plan and evaluate bioeconomy transitions to meet SDGs (see Figure 1).

Because the bioeconomy has garnered attention as a way of addressing SDGs, this section will discuss how the application of MPAST can work in an SDG context. SDG mapping requires continual improvement [23], and although this paper does not attempt a contribution to SDG mapping itself, MPAST can act as a bridge between SDG mapping and concrete goal setting for the bioeconomy by sector. To discuss how this bridge is built, we explain how the application of MPAST in Norwegian agricultural bioeconomy transitions is nested in several SDGs. We highlight three SDGs for discussion [4]: SDG 8: Decent work and economic growth; SDG 13: Climate Action; and SDG 15: Life on Land, which aims to protect endangered animal species and terrestrial ecosystems.

The critical assessment by Spangenberg (2017) [7] of the SDGs regarding requiring little to nothing from business and consumers, the counteracting drivers and pressures, and the lack of agency represented in the SDGs is of particular relevance for applying MPAST for bioeconomy transitions. MPAST provides a systematic framework for incorporating elements of agency and the identification of counteracting pressures and drivers over time in one geographic context. Because MPAST is sector-specific and has one geographic context per application, it does not address the criticism regarding pressures and drivers counteracting each other in different geographic contexts. For example, in Figure 3, the case application given in section three relates to SDGs 8, 13, and 15. Accomplishing these SDGs requires economic growth while addressing environmental issues related to climate and land use. These have counteracting pressures and drivers and require little to nothing from business, and agency is not well represented. At its core, sustainable development is aiming to address the counteracting pressure between economic development and climate action (in addition to all environmental impact 
categories). The bioeconomy is meant to help address this, but as bioeconomic industries develop, this puts pressure on life on land as this will require the farming of bio-resources. In addition, although the bioeconomy is politically assumed to be a win-win for rural areas and the environment, Burton and Fuglestad (2020) [12] indicate that this is unlikely as biotechnologies improve. Life on land also has a counteracting pressure with climate action as greenhouse gas emissions from agriculture, and the changes in land use necessitated by a bioeconomy transition, have a significant effect on mitigating climate change [10].

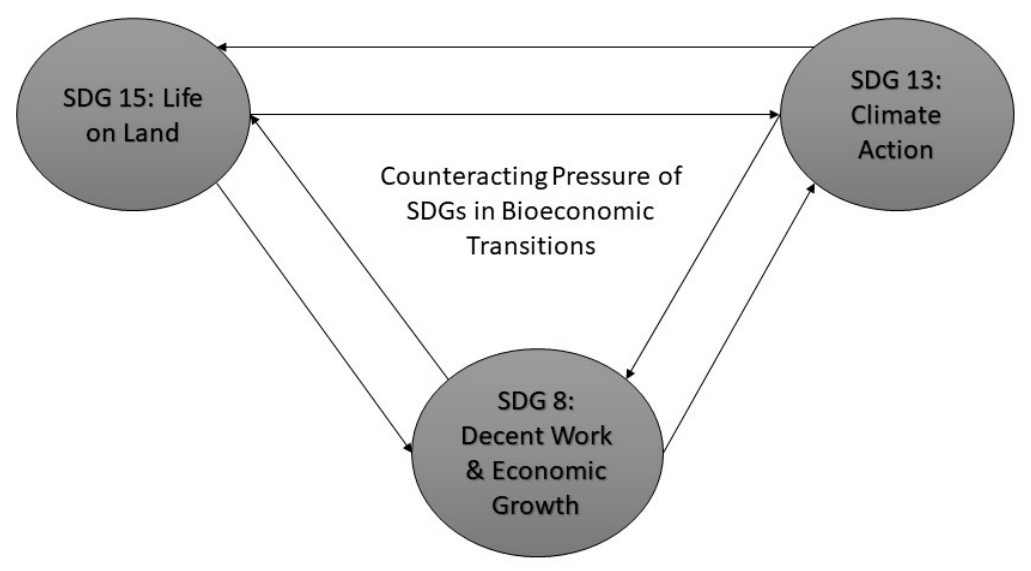

Figure 3. SDGs examples highlighting counteracting pressure.

MPAST facilitates pathways to address these criticisms when bioeconomy transitions are the means to reach SDGs. The SPADE analysis requires a stakeholder assessment. It does not provide the agency for SDGs, but it provides a tool for the incorporation of agency in the planning of SDG implementation with bioeconomy transitions. MPAST is centered on planning bioeconomy transitions by sector using established frameworks and works as a "framework of frameworks". The focus on sectors and stakeholders, rather than specifically the state, requires more of business in particular sectors. Business stakeholders become part of the process of setting the goal posts for bioeconomy transitions (MPAST Phase 1 and 2) and developing the transition pathway for meeting bioeconomy (and hence SDG) goals (MPAST Phase 3). Counteracting drivers and pressure are more easily identified with the application of system archetypes to problems and solutions, as illustrated with the laboratory meat example in Section 3.3.

The economics of bioeconomy transitions are complex, and the boundaries of traditional sectors may stretch or change shape in transitions as value-chains in the bioeconomy are not yet well-defined [46]. Social considerations such as the development of social and cultural capital also contribute strongly to the complexity of transitions-for example, by inhibiting adoption of agri-environmental policies that fall outside cultural norms [13] or facilitating collaborative actions within farming communities [14]. However, the social science perspective is not well developed in bioeconomy transitions literature [9]. This is especially problematic in the case of Norwegian agriculture because, as noted above, agriculture's value in the bioeconomy is as much (or more) its contribution to wider society as the economic value of production.

Stakeholder perspectives contributing to shared visions of bioeconomy solutions and transitions through iterative strategic planning to shape new sectors and value-chains can facilitate the bioeconomy as a means of addressing SDGs. The development and use of MPAST seems straightforward and clear as a process of using archetype mapping for transitions, but this was not clear at the beginning of MPAST development. There is an array of archetypes/frameworks that can be applied to sustainable bioeconomy transitions. There is no systematic method for applying these frameworks. At the beginning of the analysis of the Norwegian agricultural bioeconomy case, we identified many relevant archetypes and mapping frameworks that were relevant for different stages of bioeconomy transitions. 
We knew that we needed to use systems archetypes in the analysis because of the systemic nature of SDGs. However, the arbitrary and unsystematic process of using system archetypes for bioeconomy transitions necessitated the development of MPAST.

There are limitations of the MPAST framework that require it to be developed for a more general context. As stated, we developed this framework to analyze the Norwegian agricultural case because of a lack of a mapping methodology that met the needs of our research design. While we see the potential to develop this framework to other contexts, further empirical work is required. Although we used Norwegian agricultural data in this study, this could also be applied in other geographic contexts using country specific data (or in other industries with industry specific data). Further applications in other contexts beyond Norwegian agriculture will allow further development of the MPAST framework. In addition, as new SDG mapping evolves, as seen in Dalampira \& Nastis (2019) [23], MPAST will need to develop to match this evolution.

\section{Conclusions}

MPAST is a methodological framework using a systems engineering approach that maps processes for bioeconomy transitions; it can more easily be described as a "framework of frameworks". MPAST is designed to make a clear identification of start and finish lines in transitions and the pathway between using a systems approach. One could argue that MPAST could be used in any transition, but it is particularly useful for the bioeconomy. The bioeconomy has either weak/nonexistent or differing visions (solution states) of what the bioeconomy should be [31,32], and using MPAST is a way to systematically incorporate stakeholder perspectives into the analysis of bioeconomy development with a focus on sectors. Stakeholder perspectives are of particular importance given the focus the bioeconomy has had as a solution to addressing SDGs, and criticism of SDGs has shown them to be weak on agency. In addition to agency, SDGs have been criticized for their counteracting pressures and drivers in the same or different contexts. The systematic use of systemic frameworks helps identify what these drivers and pressures are, which is required for strategic planning to address them. Although there are important criticisms of the SDGs, the criticism itself can help provide the solutions.

Author Contributions: Writing and methodology, E.P., R.B. and C.H.; review, C.H. All authors have read and agreed to the published version of the manuscript.

Funding: This research was funded by the Norwegian Research Council, BioSmart and Protein 2.0 projects; grant numbers 244608 and 294777. The APC was funded by Ruralis.

Conflicts of Interest: The authors declare no conflict of interest.

\section{References}

1. Zilberman, D.; Kim, E.; Kirschner, S.; Kaplan, S.; Reeves, J. Technology and the future bioeconomy. Agric. Econ. 2013, 44, 95-102. [CrossRef]

2. Heimann, T. Bioeconomy and SDGs: Does the bioeconomy support the achievement of the SDGs? Earth's Future 2019, 7, 43-57. [CrossRef]

3. Ramcilovic-Suominen, S.; Pülzl, H. Sustainable development-a 'selling point' of the emerging EU bioeconomy policy framework? J. Clean. Prod. 2018, 172, 4170-4180. [CrossRef]

4. United Nations General Assembly (UN). Transforming our World: The 2030 Agenda for Sustainable Development; United Nations: New York, NY, USA, 2015.

5. Le Blanc, D. Towards integration at last? The sustainable development goals as a network of targets. Sustain. Dev. 2015, 23, 176-187. [CrossRef]

6. Pradhan, P.; Costa, L.; Rybski, D.; Lucht, W.; Kropp, J.P. A systematic study of Sustainable Development Goal (SDG) interactions. Earth's Future 2017, 5, 1169-1179. [CrossRef]

7. Spangenberg, J.H. Hot air or comprehensive progress? A critical assessment of the SDGs. Sustain. Dev. 2017, 25, 311-321. [CrossRef]

8. Wong, R.; Heijden, J. Avoidance of conflicts and trade-offs: A challenge for the policy integration of the United Nations Sustainable Development Goals. Sustain. Dev. 2019, 27, 1-8. [CrossRef] 
9. Sanz-Hernández, A.; Esteban, E.; Garrido, P. Transition to a bioeconomy: Perspectives from social sciences. J. Clean. Prod. 2019, 224, 107-119. [CrossRef]

10. Parry, M.L. Climate Change and World Agriculture; Routledge: London, UK, 2019.

11. Olsson, E.G.A.; Rönningen, K.; Hanssen, S.K.; Wehn, S. The interrelationship of biodiversity and rural viability: Sustainability assessment, land use scenarios and Norwegian mountains in a European context. J. Environ. Assess. Policy Manag. 2011, 13, 251-284. [CrossRef]

12. Burton, R.J.F.; Fuglestad, E. Etter Oljen: Vår bioøkonomiske fremtid. Bortenfor bioøkonomien. ("Beyond the Bioeconomy"); Burton, R.J.F., Forbord, M., Ellingsted, M.B., Fuglestad, E., Eds.; Cappelen Damm: Oslo, Norway, 2020.

13. Burton, R.J.F.; Kuczera, C.; Schwarz, G. Exploring farmers' cultural resistance to voluntary agri-environmental schemes. Sociol. Rural. 2008, 48, 16-37. [CrossRef]

14. Sutherland, L.-A.; Burton, R.J.F. Good Farmers, Good Neighbours? The role of cultural capital in social capital development a Scottish farming community. Sociol. Rural. 2012, 51, 238-255. [CrossRef]

15. Mustalahti, I. The responsive bioeconomy: The need for inclusion of citizens and environmental capability in the forest based bioeconomy. J. Clean. Prod. 2018, 172, 3781-3790. [CrossRef]

16. Skene, K.R.; Malcolm, J. Using the SDGs to nurture connectivity and promote change. Des. J. 2019, 22, 1629-1646. [CrossRef]

17. Stafford-Smith, M.; Griggs, D.; Gaffney, O.; Ullah, F.; Reyers, B.; O'Connell, D. Integration: The key to implementing the Sustainable Development Goals. Sustain. Sci. 2017, 12, 911. [CrossRef] [PubMed]

18. Senge, P.M. The Fifth Discipline Fieldbook: Strategies and Tools for Building a Learning Organization; Doubleday: New York, NY, USA, 1995. [CrossRef]

19. Braun, W. The System Archetypes. The Systems Modeling Workbook. 2002. Available online: http: //www.albany.edu/faculty/gpr/PAD724/724WebArticles/sys_archetypes.pdf (accessed on 17 August 2020).

20. Wolstenholme, E. Using generic system archetypes to support thinking and modelling. Syst. Dyn. Rev. 2004, 20, 341-356. [CrossRef]

21. Probst, G.; Bassi, A. Tackling Complexity: A Systemic Approach for Decision Maker; Routledge: New York, NY, USA, 2017. [CrossRef]

22. Haskins, C. Using Patterns to Transition Systems Engineering from a Technological to Social Context. Syst. Eng. 2008, 11, 147-155. [CrossRef]

23. Dalampira, E.-S.; Nastis, S.A. Mapping Sustainable Development Goals: A network analysis framework. Sustain. Dev. 2020, 28, 46-55. [CrossRef]

24. Bauer, F. Narratives of biorefinery innovation for the bioeconomy: Conflict, consensus or confusion? Env. Inno. Soc. Trans. 2018, 28, 96-107. [CrossRef]

25. Palmer, E. Systems Engineering Applied to Evaluate Social Systems: Analyzing Systemic Challenges to the Norwegian Welfare State; The University of Bergen: Bergen, Norway, 2017.

26. Szajnfarber, Z.; Gralla, E. Qualitative methods for engineering systems: Why we need them and how to use them. Syst. Eng. 2017, 20, 497-511. [CrossRef]

27. Bocken, N.M.; Short, S.W.; Rana, P.; Evans, S. A literature and practice review to develop sustainable business model archetypes. J. Clean. Prod. 2014, 65, 42-56. [CrossRef]

28. Schellnhuber, H.J.; Lüdeke, M.K.B.; Petschel-Held, G. The syndromes approach to scaling describing global change on an intermediate functional scale. Integr. Assess. 2002, 3, 201-219. [CrossRef]

29. Haskins, C. Systems Engineering Analyzed, Synthesized, and Applied to Sustainable Industrial Park Development; Norwegian University of Science and Technology: Trondheim, Norway, 2008.

30. Allen, C.; Metternicht, G.; Wiedmann, T. An Iterative Framework for National Scenario Modelling for the Sustainable Development Goals (SDGs). Sustain. Dev. 2017, 25, 372-385. [CrossRef]

31. Meyer, R. Bioeconomy strategies: Contexts, visions, guiding implementation principles and resulting debates. Sustainability 2017, 9, 1031. [CrossRef]

32. Hansen, L.; Bjørkhaug, H. Visions and expectations for the Norwegian bioeconomy. Sustainability 2017, 9 , 341. [CrossRef]

33. Valseth, M.S. Innovation Norway supporting the development of an algae industry in Norway. In Proceedings of the Workshop, Nordic Algae Network and Blue Bio, Ås, Norway, 15 November 2012.

34. Kleinschmit, D.; Lindstad, B.H.; Thorsen, B.J.; Toppinen, A.; Roos, A.; Baardsen, S. Shades of green: A social scientific view on bioeconomy in the forest sector. Scand. J. For. Res. 2014, 29, 402-410. [CrossRef] 
35. Norwegian Government. Known Resources, Limitless Possibilities; The Government's Bioeconomy Strategy; The Ministry of Trade, Industry and Fisheries: Oslo, Norway, 2016.

36. Ellingson, W. Rural Second Homes: A Narrative of De-Centralisation. Sociol. Rural. 2017, 57, 229-244. [CrossRef]

37. Organisation for Economic Co-operation and Development (OECD). Bio-Economy and the Sustainability of the Agricultural and Food System: Opportunities and Policy Challenges; OECD: Joint Working Party on Agriculture and the Environment: Paris, France, 2018.

38. Schellnhuber, H.J.; Block, A.; Cassel-Gintz, M.; Kropp, J.; Lammel, G.; Petschel-Held, G. Syndromes of global change. GAIA-Ecol. Perspect. Sci. Soc. 1997, 6, 18-33. [CrossRef]

39. Eisenack, K. Archetypes of Adaptation to Climate Change. In Human-Nature Interactions in the Anthropocene; Routledge: New York, NY, USA, 2012. [CrossRef]

40. Cavallo, M.; Gerussi, E. Bioeconomy, circular economy and industrial symbiosis: Towards a new concept of productive processes. Eco-Ind. Parks 2015, 43-47.

41. Holmberg, J.; Robèrt, K.H. Backcasting-A framework for strategic planning. International. J. Sustain. Dev. World Ecol. 2000, 7, 291-308. [CrossRef]

42. Bjørkhaug, H.; Hansen, L.; Zahl-Thanem, A. Sektorvise Scenarier for Bioøkonomien. (Sectoral Scenarios for the Bioeconomy); Ruralis Rapport; RURALIS: Trondheim, Norway, 2018; p. 4. Available online: https://ruralis.no/wp-content/uploads/2018/08/r4_18-sektorvise-scenarier-for-biokonomienh-bjrkhaug-1--hansen-og-a--zahl-thanem.pdf (accessed on 29 June 2020).

43. Marchetti, M.; Vizzarri, M.; Lasserre, B.; Sallustio, L.; Tavone, A. Natural capital and bioeconomy: Challenges and opportunities for forestry. Ann. Silvic. Res. 2014, 38, 62-73.

44. Burton, R.J.F. The potential impact of synthetic animal protein on livestock production: The new "war against agriculture"? J. Rural Stud. 2019, 68, 33-45. [CrossRef]

45. Smetana, S.; Mathys, A.; Knoch, A.; Heinz, V. Meat alternatives: Life cycle analysis of most known meat alternatives. Int. J. Life Cycle Assess. 2015, 20, 1254-1267. [CrossRef]

46. Hermans, F. The potential contribution of transition theory to the analysis of bioclusters and their role in the transition to a bioeconomy. Biofuels Bioprod. Biorefin. 2018, 12, 265-276. [CrossRef]

(C) 2020 by the authors. Licensee MDPI, Basel, Switzerland. This article is an open access article distributed under the terms and conditions of the Creative Commons Attribution (CC BY) license (http://creativecommons.org/licenses/by/4.0/). 